\title{
Exceptional Symbiosis Between Tumors: A Case of Gastric Signet Ring Cell Metastasis in Chromophobe Carcinoma of the Kidney
}

This article was published in the following Dove Press journal: Research and Reports in Urology

\author{
Miriam Cieri (D) \\ Silvia Carrara ${ }^{2}$ \\ Piergiuseppe Colombo (ID ${ }^{1}$ \\ 'Department of Pathology, Humanitas \\ Clinical and Research Center - IRCCS, \\ Rozzano, Milan, Italy; ${ }^{2}$ Department of \\ Endoscopy, Humanitas Clinical and \\ Research Center - IRCCS, Rozzano, \\ Milan, Italy
}

\begin{abstract}
Tumor-to-tumor metastasis is the presence of a metastatic deposit within a second malignant primary, and its identification could be challenging, particularly when the latter malignancy has not yet been discovered. Renal cell carcinoma is one of the known recipients. Here we present a 52 years old woman who presented with a small nodule in the left kidney, which had a biphasic cell proliferation, chromophobe type, and signet-ring cell type for which we suggested to investigate the presence of a second tumor of gastrointestinal origin. We present this case for the rarity of its presentation, for the peculiar histological symbiosis we found between the two tumor entities, and for the challenging diagnosis due to the presence of an occult aggressive primary tumor.
\end{abstract}

Keywords: tumor-to-tumor metastasis, gastric signet-ring cell carcinoma, chromophobe carcinoma, kidney metastasis, renal cell carcinoma, cancer of unknown primary

\section{Introduction}

Metastasis of a tumor within a second tumor is a notable phenomenon, known since the mid-1800s as "tumor-to-tumor metastasis". ${ }^{1}$ More recently in the 1960s, it has been well characterized by Ortega $\mathrm{P}$ and Campbell LV, and later many different tumor histotypes capable of depositing within a second tumor have been identified. $^{2-4}$ Among these, kidney carcinoma is considered a not unusual recipient of metastases, with exceptional cases of primary gastric carcinoma described in the literature. ${ }^{4-6}$ Here we present a case of undiagnosed signet-ring cell carcinoma of the stomach that has metastasized within chromophobe carcinoma of the kidney.

\section{Case}

A 52 years old woman, who had no pre-existing medical condition nor prior surgical history, presented to our institution in October 2019, reporting abdominal pain. Ultrasound imaging performed at another Institution showed an ill-defined cortical mass arising from the upper pole of the left kidney, subsequently confirmed by computed tomography. Therefore, the patient underwent robotic partial nephrectomy, and discharged on the third post-operative day with regular clinical follow-up, ensured about the good prognosis of the disease.

Gross pathological examination of the surgical specimen revealed a pale-yellow nodule measuring $3.2 \mathrm{~cm}$, with solid and hemorrhagic areas (Figure 1A). Histology documented a clear cell carcinoma composed of cells with distinct cell borders and
Correspondence: Piergiuseppe Colombo Department of Pathology, Humanitas Clinical and Research Center - IRCCS Rozzano, via Manzoni 56, Rozzano, Milano CAP 20089, Italy

Email piergiuseppe.colombo@humanitas.it
Research and Reports in Urology 2021:13 45-48 

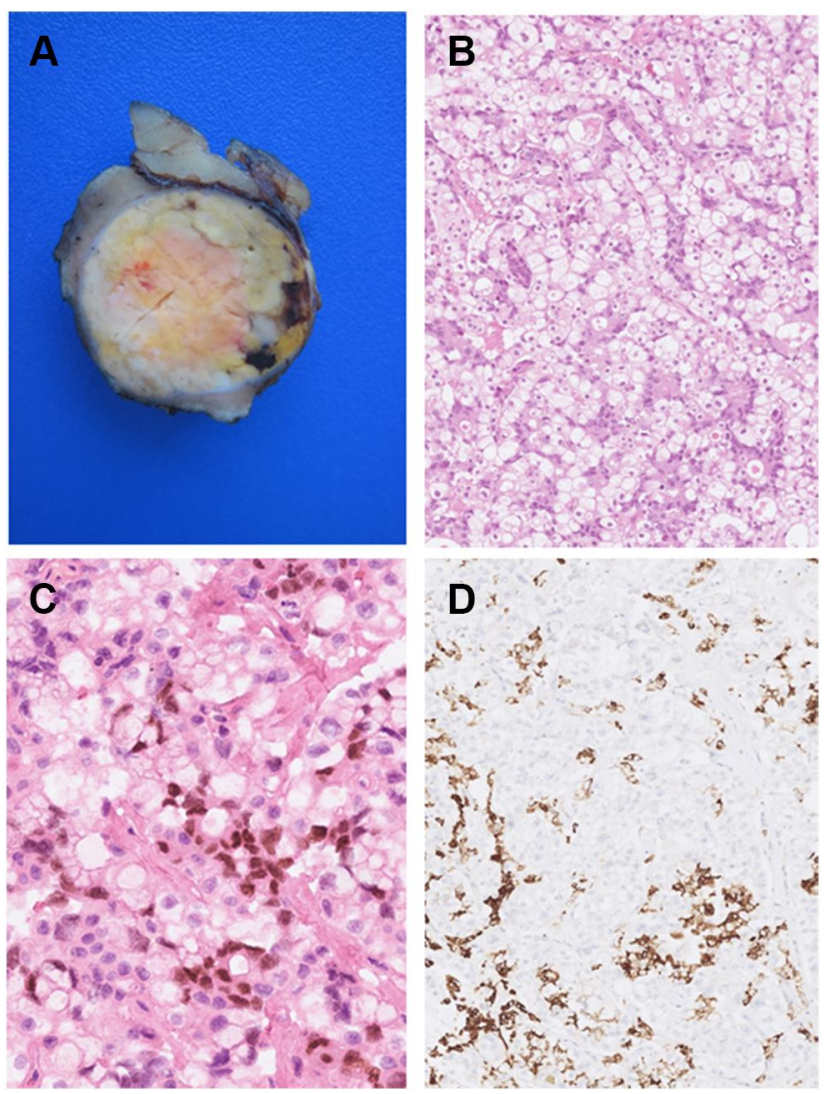

Figure I (A) Gross appearance of primary renal tumor, showed yellowish, solid mass surrounded by a thin layer of normal kidney parenchyma. (B) The tumor showed a biphasic proliferation of glandular metastatic structures admixed within chromophobe renal cell carcinoma in a perfect symbiosis (hematoxylin and eosin; original magnification $\times 200$ ). (C) Intestinal marker CDX2 was expressed only in scattered cells arguing for gastric origin. (D) Gastric tumor cells showing typical expression of hepatic marker HSA.

occasional perinuclear halos. Among this component, a second population of cells was found, arranged in clusters either with microglandular structures or in a singlecell pattern. Some of the latter showed intracytoplasmic lumen with signet-ring cell appearance, giving a biphasic pattern to the tumor (Figure 1B).

Immunohistochemically, the clear cell component expressed CK7 with diffuse pattern, CD117, PAX8 focally (data not shown), while signet-ring cells showed the expression of intestinal marker CDX2 and hepatic marker HSA (Figure 1C and D). The microscopic differential diagnosis of our tumor included atypical oncocytoma, unclassified renal cell carcinoma and metastatic carcinoma. Immunohistochemical findings led to the final diagnosis of metastatic gastric signet-ring cell carcinoma into a chromophobe renal cell carcinoma (tumor-to-tumor metastasis). Indeed, we suggest clinician to investigate further to check for a gastric cancer.
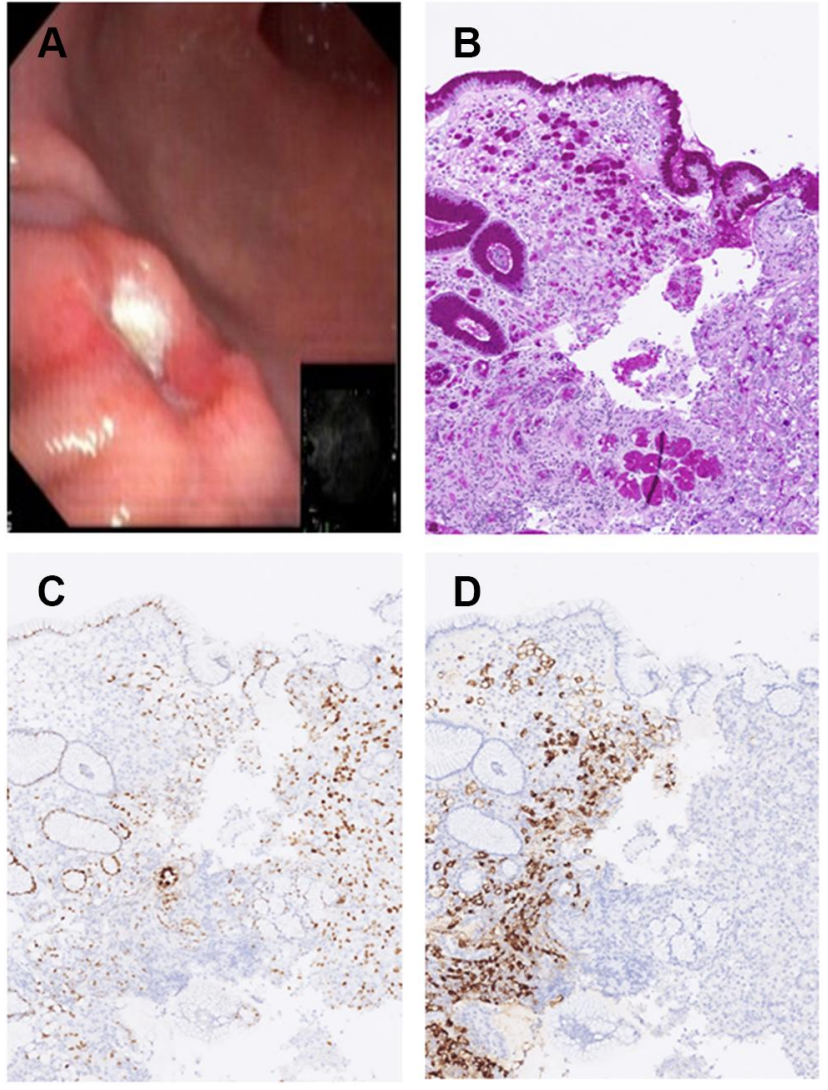

Figure 2 (A) Endoscopy showing a coin-shaped ulcerated lesion. (B) Alcian-Pas showing deposition of mucin inside signet-ring cell cytoplasm, confirming glandular differentiation. (C) CDX2 and (D) HSA expression as in the metastatic counterpart.

Nevertheless, in February 2020 gastric endoscopy performed at another institution did not show any lesions. Unfortunately, due to the rapid spread of coronavirus pandemic in Lombardy, the patient delayed the follow-up appointment and she was referred to our institution seven months later.

At endoscopic exploration, a gastric antral ulcerated lesion measuring about $1 \mathrm{~cm}$ was found (Figure 2A). The biopsy specimen consisted of a neoplastic proliferation of tubular structures and signet-ring cells, diffusely positive for CDX2, HSA, and CK7, with intracytoplasmic vacuoles containing mucin resulted positive to Alcian-Pas stain, and negative for PAX8, consistent with a primitive signet-ring cell and tubular gastric carcinoma (Figure 2B and D). Following discussion with Gastro-Intestinal Board of our Institution, a staging laparoscopy was performed and it excluded other secondary localizations in the abdomen. As of today, the patient is alive and she has started neoadjuvant chemotherapy. 


\section{Discussion}

Onuigbo $\mathrm{W}$ first described metastasis from one tumor (the donor) to another neoplasm (the recipient) in 1848, followed by various authors who reported donor neoplasms arising from breast, lung, skin, and prostate. ${ }^{1,7-11}$ Commonly reported recipient tumors are renal cell tumors, meningioma, and sarcoma; with kidney tumors being the most common. ${ }^{12,13}$ To date, clear cell renal cell carcinoma (ccRCC) is by far the most common recipient among malignant tumors. ${ }^{14}$

Several physio-pathological mechanisms can explain this phenomenon, but many of them are still unknown.

Two different theories have been described for the underlying mechanisms of tumor-to-tumor metastasis. The first is the "seed and soil" theory, suggesting that the metastatic tumor cells (seeds) favor a suitable niche (soil) for their growth and proliferation. ${ }^{15,16}$ This hypothesis was challenged by the "mechanical entrapment theory", which suggests that tumor metastasis was fostered by hemodynamic factors of the vascular network, as these factors could affect the delivery of metastatic tumor cells. ${ }^{17}$

In ccRCC, the inactivation of von Hippel Lindau tumor suppressor gene increases hypoxia-inducible factor, which in turn increases vascular endothelial growth factor, determining the high vascularization of ccRCC. From a metabolic point of view, the rich glycogen and lipid content of ccRCC may make it an attractive and favorable environment for metastases. Thus, even decades ago, renal cell carcinoma was considered the best recipient of tumorto-tumor metastasis. ${ }^{12}$

Although renal cell carcinomas are the main hosts of metastasis in the tumor-to-tumor phenomenon, the metastasis of gastric adenocarcinoma to renal cancer seems to be a very rare phenomenon. The present case is very similar to that described by Sakai et al in 2010, where the authors reported a patient with a known primary signet-ring cell carcinoma metastasized to a clear cell carcinoma of the kidney. ${ }^{4}$ Conversely, in our case, the primary neoplasm was unknown. To the best of our knowledge, this is the first case report of a gastric signet-ring cell carcinoma metastasis to a chromophobe renal cell carcinoma, tumorto-tumor metastasis, and the third case of metastasis to chromophobe renal cell carcinoma when using MEDLINE database. ${ }^{4}$ Previously, a colorectal carcinoma metastasis and a prostate adenocarcinoma metastasis to chromophobe renal cell carcinomas were described by Skin et al and Cavalcante et al, respectively. ${ }^{18,19}$
The case we presented here is peculiar because of the strong symbiosis between two different types of tumor cells. In fact, at a first microscope examination, it could be difficult to discriminate between metastatic tumor and renal tumor. To complicate the picture, in literature are described cases of renal cell carcinoma with mucoid cell production and sometimes the presence of foci of glandular differentiation. ${ }^{20}$ Furthermore, a diagnosis of metastasis to renal cell carcinoma is challenging when the primary malignancy has not yet been discovered. ${ }^{21}$ In these rare events, it is possible to discern between the two differential diagnosis by immunohistochemical analysis such as marker of renal origin PAX8 and intestinal origin CDX2. Infrequently, signet-ring cell carcinoma exhibits focal "hepatoid" differentiation, as in the present case. This differentiation can be detected through immunopositivity to HSA (hepatocyte superficial antigen), which in the present case has been documented both in primary gastric carcinoma and in its metastasis.

Even though the most common incidental finding in the kidney is renal cell carcinoma, it is important for both clinicians and surgical pathologists to keep in mind the possibility of the unusual tumor-to-tumor metastasis phenomenon for accurate diagnosis, staging, and treatment. In our case, the abdominal pain caused by the renal mass led to the accidental finding of gastric tumor, nevertheless, misinterpretation of the clinical picture and nonspecificity of clinical signs and symptoms caused a diagnostic delay.

\section{Ethics Approval and Informed Consent}

All procedures performed in this report involving human participants were in accordance with the ethical standards of the institutional and/or national research committee and with the 1964 Helsinki declaration and its later amendments or comparable ethical standards. Written informed consent has been provided by the patient to have the case details and any accompanying images published. It was approved by Humanitas Clinical and Research Center Ethics Committee to publish the case details.

\section{Author Contributions}

All authors made a significant contribution to the work reported, whether that is in the conception, study design, execution, acquisition of data, analysis and interpretation, or in all these areas; took part in drafting, revising or 
critically reviewing the article; gave final approval of the version to be published; have agreed on the journal to which the article has been submitted; and agree to be accountable for all aspects of the work.

\section{Disclosure}

The authors declare that there are no potential conflicts of interest.

\section{References}

1. Onuigbo W. An early description of cancer-to-cancer metastasis in 1848. N Z Med J. 2005;118(1210):U1315.

2. Ortega P Jr, Li IY, Shimkin M. Metastasis of neoplasms to other neoplasms. Ann West Med Surg. 1951;7:601-609.

3. Campbell LV Jr, Gilbert E, Chamberlain CR Jr, Watne AL. Metastases of cancer to cancer. Cancer. 1968;22(3):635-643. doi:10.1002/10970142(196809)22:3<635::AID-CNCR2820220320>3.0.CO;2-O

4. Sakai Y, Kanomata N, Itami H, Kajimoto K, Sakuma T, Ohbayashi C. Signet-ring cell carcinoma of the stomach metastasizing to renal cell carcinoma: a case report and review of the literature. Kobe J Med Sci. 2010;55(6):E122-E131.

5. Patel S, Rajalakshmi BR, Manjunath GV. Histopathologic findings in autopsies with emphasis on interesting and incidental findings-a pathologist's perspective. J Clin Diagn Res. 2016;10(11):EC08EC12. doi:10.7860/JCDR/2016/21106.8850

6. Ricketts R, Tamboli P, Czerniak B, Guo CC. Tumor-to-tumor metastasis: report of 2 cases of metastatic carcinoma to angiomyolipoma of the kidney. Arch Pathol Lab Med. 2008;132(6):1016-1020. doi:10.1043/1543-2165(2008)132[1016:TMROCO]2.0.CO;2

7. Savoiardo M, Lodrini S. Hypodense area within a meningioma: metastasis from breast cancer. Neuroradiology. 1980;20(2):107-110. doi:10.1007/BF00339557

8. Fornelli A, Bacci A, Collina G, Eusebi V. Breast carcinoma metastatic to meningioma: review of the literature and description of 2 new cases. Pathologica. 1995;87(5):506-512.
9. Pamphlett R. Carcinoma metastasis to meningioma. J Neurol Neurosurg Psychiatry. 1984;47(5):561-563. doi:10.1136/jnnp.47.5.561

10. Takei H, Powell SZ. Tumor-to-tumor metastasis to the central nervous system. Neuropathology. 2009;29(3):303-308. doi:10.1111/ j.1440-1789.2008.00952.x

11. Döring L. Metastasis of carcinoma of prostate to meningioma. Virchows Arch a Pathol Anat Histol. 1975;366(1):87-91. doi:10.1007/BF00438681

12. Sella A, Ro JY. Renal cell cancer: best recipient of tumor-to-tumor metastasis. Urology. 1987;30:35-38.

13. Petraki C, Vaslamatzis $M$, Argyrakos $T$, et al. Tumor to tumor metastasis. Int J Surg Pathol. 2016;11(2):127-135. doi:10.1177/ 106689690301100214

14. Rabson SM, Stier PL, Baumgartner JC, Rosenbaum D. Metastasis of cancer to cancer. Am J Clin Pathol. 1954;24:572-579. doi:10.1093/ ajcp/24.5.572

15. Paget $\mathrm{S}$. The distribution of secondary growths in cancer of the breast. Lancet. 1889;1:571-573. doi:10.1016/S0140-6736(00)49915-0

16. Fidler I. The pathogenesis of cancer metastasis: the "seed and soil" hypothesis revisited. Nat Rev Cancer. 2003;3:453-458. doi:10.1038/ nrc1098

17. Ewing JA. A Treatise on Tumors. Philadelphia, PA: Saunders; 1928.

18. Skin T, Kan T, Sato F, Mimata H. Tumor-to-tumor metastasis to chromophobe renal cell carcinoma: a first report. Case Rep Urol. 2011;2011.

19. Cavalcante A, Cordeiro MD, Sierra PS, et al. A rare case of tumor-totumor metastasis: prostate cancer to chromophobe renal cell carcinoma. Urol Case Rep. 2018;23:17-18.

20. Sirohi D, Smith SC, Ohe C, et al. Renal cell carcinoma, unclassified with medullary phenotype: poorly differentiated adenocarcinomas overlapping with renal medullary carcinoma. Hum Pathol. 2017;67:134-145. doi:10.1016/j.humpath.2017.07.006

21. Colombo P, Tondulli L, Masci G, et al. Oral ulcer as an exclusive sign of gastric cancer: report of a rare case. BMC Cancer. 2005;5:117. doi:10.1186/1471-2407-5-117
Research and Reports in Urology

\section{Publish your work in this journal}

Research and Reports in Urology is an international, peer-reviewed, open access journal publishing original research, reports, editorials, reviews and commentaries on all aspects of adult and pediatric urology in the clinic and laboratory including the following topics: Pathology, pathophysiology of urological disease; Investigation and treatment of urological disease; Pharmacology of drugs used for the treatment of urological disease. The manuscript management system is completely online and includes a very quick and fair peer-review system, which is all easy to use. Visit http://www.dovepress.com/ testimonials.php to read real quotes from published authors. 